\title{
Interspecific variation in the diets of herbivores in an industrial environment: implications for exposure to fluoride emissions
}

\author{
Naomi E. Davis ${ }^{1,4}$, Clare E. Death ${ }^{2}$, Graeme Coulson ${ }^{1}$, Lora Newby ${ }^{3}$ and Jasmin Hufschmid ${ }^{2}$ \\ ${ }^{1}$ School of BioSciences, The University of Melbourne, Victoria, Australia \\ ${ }^{2}$ Faculty of Veterinary and Agricultural Sciences, The University of Melbourne, Victoria, Australia \\ ${ }^{3}$ Portland Aluminium, Quarry Rd, Portland, Victoria, Australia \\ ${ }^{4}$ Corresponding author: ndavis@unimelb.edu.au; +61 427357388
}

Keywords: marsupial; kangaroo; wallaby; industrial pollutant; fluoride; aluminium smelting; diet

Running header: Herbivore diets in an industrial environment

\section{Acknowledgements}

We thank Jodie Gould (Portland Aluminium) for technical assistance and contributions to the manuscript, and Ron Jeffries (Portland Aluminium) for practical assistance. We would like to acknowledge assistance from Ian Beveridge, Catharina Vendl, Paul Benham and Ian Freeman (The University of Melbourne, Faculty of Veterinary and Agricultural Sciences). Portland Aluminium funded and provided logistical support for this research. Comments by two anonymous reviewers greatly improved the manuscript. 


\begin{abstract}
Atmospheric fluorides (gaseous and particulate) are deposited on, and absorbed by, vegetation. Ingested fluoride accumulates in calcified tissues of vertebrates and if it is excessive, it may lead to dental and skeletal fluorosis. The prevalence, form and severity of the effects vary greatly between species. Foraging strategy can be an important determinant of fluoride exposure in herbivores, because foliar fluoride concentrations vary between plant species, for example, according to vertical and lateral position in the vegetation. We combined microhistological analysis of diet and analysis of foliar fluoride levels to examine interspecific variation in dietary fluoride exposure of macropodid marsupials (swamp wallaby Wallabia bicolor, red-necked wallaby Notamacropus rufogriseus, and eastern grey kangaroo Macropus giganteus), in the buffer zone of an aluminium smelter in Victoria, Australia. Dietary niche differentiation between species was evident. The swamp wallaby and the red-necked wallaby were browsers or mixed feeders, depending on the classification system used. The eastern grey kangaroo was a grazer, consuming almost entirely grasses. However, foliar fluoride did not vary significantly between the main plant groups consumed. Our results indicate that interspecific variation in diet at this site is unlikely to explain variation in fluoride exposure.
\end{abstract}

\title{
Introduction
}

Wildlife exposed to industrial pollutants can be affected by a wide range of sub-clinical to lethal impacts (e.g., Newman et al. 1988; Ross et al. 1996; Gleeson and Gleeson 2012). At contaminated sites, it is important to identify species susceptible to pollution, and their pathways of exposure (McBee and Bickham 1990; De Lange et al. 2009). Vegetated buffer zones around industrial facilities, may function as pollutant sinks (Smith 1974; Murphy et al. 1977; Murray 1982) whilst supporting significant animal and plant biodiversity. Importantly, these zones contain novel plant assemblages (Doley 1986; Weinstein and Davison 2003) and ecological interactions within them may differ from those in natural environments (Murray 1981; Lundholm and Richardson 2010)

Fluorine is a significant natural and industrial contaminant that forms fluoride complexes in the environment (Weinstein and Davison 2004). While fluorides are a natural component of all environments and may be naturally high in ground water and volcanic ash, solubility in most soils is low and natural concentrations are generally low, with background fluoride content in vegetation generally <10 $\mu \mathrm{gF} / \mathrm{g}$ (WHO 2000; Divan Jr et al. 2008). However, fluorides may be released in high concentrations as industrial by-products (WHO 2000). The primary anthropogenic sources of these fluoride emissions are the aluminium industry, oil drilling and refining, the chemical and plastics industries, agricultural pesticide manufacturers, glass and ceramics factories, dye manufacturers and manufacturers of metal parts (NPI 2014). Except under occupational exposure conditions, respirable intake of fluorides is almost negligible, and total fluoride intake depends on ingestion (WHO 2000).

Gaseous and particulate emissions of fluoride are deposited on, and absorbed by, vegetation surrounding fluoride sources (Murray 1981; Davison 1983; Doley 1986). Some plant species accumulate high concentrations of fluoride (Davison 1983) in levels that are toxic to animals (Doley 
1986), particularly in foliar margins and tips (Weinstein and Davison 2003) where it is readily accessible to herbivores (Doley 1986). Fluoride content of the vegetation around emission sources may reach 100-500 $\mu \mathrm{gF} / \mathrm{g}$ (Divan Jr et al. 2008). Following ingestion, fluoride is absorbed and accumulates in calcified tissues (Weinstein and Davison 2004). Long-term consumption of fluoride-contaminated plant material can cause fluorosis in mammals (e.g., Suttie 1980; Shupe et al. 1984; Kierdorf et al. 1996a). Ingested fluoride is deposited in bone, impacting on its structure and strength (Everett 2011) and resulting in osteofluorosis under chronic conditions, which includes pathological changes such as osteoporosis, osteosclerosis, focal and/or generalised hyperostosis and increased prevalence of degenerative joint disease (Shupe 1980: Hufschmid et al. 2015). Similarly, dental fluorosis can lead to pathological changes caused by the hypoplasia and hypomineralisation of enamel, including accelerated rates of tooth wear and loss (Fejerskov et al. 1977; Kierdorf et al. 1996b), and periodontal disease and osteomyelitis of the skull and mandible (Schultz et al. 1998), with potential consequences for fitness and longevity (Garrott et al. 2002).

In populations of free-ranging, mammalian herbivores in fluoride-contaminated areas, bone fluoride levels and the prevalence, form and severity of associated dental and skeletal lesions vary between species (Weatherell and Weidmann 1959; Shupe et al. 1984; Boivin et al. 1990). These differences are associated with interspecific variation in a range of factors that influence fluoride ingestion, absorption and biomechanical forces on bones: foraging range, activity pattern, diet, health status, longevity, metabolic factors, anatomy and timing of exposure (Palamara et al. 1984; Kierdorf et al. 1993; Vikøren and Stuve 1996; Vikøren et al. 1996; Crompton et al. 2010; Kierdorf et al. 2012; Carlson et al. 2013). Of these, diet is likely a major determinant of fluoride exposure and associated disease, because deposition and absorption of airborne fluoride compounds varies with plant species and factors such as vertical position (Doley 1986; Weinstein and Davison 2004). The vegetation canopy is the first surface available to atmospheric pollutants when they are deposited on terrestrial ecosystems (Murray 1982). The canopy reduces wind speed, which lowers the rate of deposition on leaves and other surfaces, while lower light intensity inside the canopy may reduce stomatal conductance and uptake into leaves (Doley 1986). Foliar fluoride accumulation decreases progressively according to vertical and lateral position in the canopy, from the tree stratum, to the more sheltered shrub and ground strata (Doley 1986; Bowen 1988; Narayan et al. 1994; Weinstein and Davison 2004). Further, foliar fluoride uptake and accumulation vary between plant species (Murray 1981; O'Connor and Horsman 1982; Divan Jr et al. 2008), related to plant properties such as the ratio of leaf surface area to dry weight and leaf arrangement, which influence fluoride conductance (Doley 1986), and the presence of features that increase leaf boundary layer resistance (Murray 1981). In addition, fluoride concentrations are lower in stems, roots and reproductive structures than in leaves (Doley 1986) due to shorter exposure times and/or lack of photosynthetic plant parts into which fluorides are assimilated (Salatas et al. 2009). Therefore, herbivores may be exposed to different levels of risk from fluoride contamination depending on their relative intake of different vegetation strata (Salatas et al. 2009), species and plant parts, and the site-specific degree of canopy cover. However, our understanding of the links between foliar fluoride levels, herbivore feeding strategy and rates of fluoride accumulation in the body, is limited. 
Previous work in the buffer zones of aluminium smelters has assessed the impact of fluoride emissions on eutherian mammals (Walton 1984; Suttie et al. 1987; Boulton et al. 1994; Vikøren et al. 1996). Three macropodid marsupial species (swamp wallaby Wallabia bicolor; red-necked wallaby Notamacropus rufogriseus; and eastern grey kangaroo Macropus giganteus) occur at the Portland Aluminium site in Victoria, Australia; a pre-bake facility equipped with emission-scavenging dry scrubbers (Kinhill 1980; Weinstein and Davison 2004). The swamp wallaby is classified as a browser, the red-necked wallaby an intermediate grazer/browser and the eastern grey kangaroo a grazer (Sanson 1989). Consistent with findings from previous studies of free-ranging herbivore populations in fluoride-contaminated areas (e.g., Boulton et al. 1994; Kierdorf and Kierdorf 1999; Hufschmid et al. 2011), Death et al. (2015) found that the three macropodid species at this site had significantly higher bone fluoride levels compared to nearby low-fluoride, non-industrial areas. However, the bone fluoride levels varied between species: swamp wallabies had lower mean bone fluoride levels $(1252 \pm 258$ SEM $\mu \mathrm{gF} / \mathrm{g}$ dry bone) compared to red-necked wallabies $(2551 \pm 314 \mu \mathrm{gF} / \mathrm{g})$ and eastern grey kangaroos $(2796 \pm 214 \mu \mathrm{gF} / \mathrm{g})($ Death et al 2015).

To determine whether dietary fluoride exposure explains interspecific variation in bone fluoride levels, we aimed to classify and compare the diets of the three macropodid species in this study, and measure foliar fluoride accumulation, in the industrial buffer zone of an aluminium smelter. We predicted that at the study site, where grassland occurs with little canopy cover, filtering of atmospheric fluoride by the canopy would be minimal and accumulation on grasses and forbs would be high relative to that on other plant groups. Therefore, we predicted that the grazing eastern grey kangaroo would have higher exposure to foliar fluoride than the browsing swamp wallaby, and exposure of the red-necked wallaby, a mixed feeder, would be intermediate.

\section{Methods}

\section{Study site}

The Portland Aluminium smelter is located on a coastal headland in south-western Victoria, Australia (38 $\left.23^{\prime} \mathrm{S}, 141^{\circ} 37^{\prime} \mathrm{E}\right)$. The smelter and the fluoride emissions produced by the facility are described in detail elsewhere (Coulson et al. 2000; Death et al. 2015). Briefly, the site incorporates a 200-ha buffer zone that consists of a mixture of farmland pasture, blue gum (Eucalyptus globulus) plantations, and intact and re-vegetated patches of native vegetation (Kinhill 1980), including coastal heathland and wetland, as well as exotic shrubs and trees planted as shelterbelts (Coulson et al. 2000).

\section{Foliar fluoride sampling}

Fluoride levels in grasses and forbs at the Portland Aluminium smelter were measured throughout each year between 2008 and 2013. Grass samples were collected two or three times per month at 19 fixed sites around the smelter 0.2-6.0 km from the central emission point (Fig 1). These sampling points were retained from a more intensive, systematic grid of sampling points because they represented the 
modelled exposure surface most accurately (Portland Aluminium, unpublished data). Ground layer forage species were sampled in approximate proportion to their abundance; hence samples consisted primarily of grasses and the forbs Medicago sativa and Trifolium species. Shears were used to cut a sub-sample of c. $10 \mathrm{~g}$ of grasses and forbs to a height of $25 \mathrm{~mm}$ above the ground, representing the forage height normally grazed by herbivores, within a $2-5 \mathrm{~m}^{2}$ area at each site. Green foliage was sampled where possible.

Fluoride levels on fern and tree/shrub material were measured at the same locations from which grass/forb material was sampled during summer (two to three times per month in January and February) and winter (two to three times per month in July and August) 2013. A total of c. $10 \mathrm{~g}$ of leaf material, was collected in approximate proportion to the relative abundance of all tree and shrub species present at each site (not all tree and shrub species were present at all sites): Eucalyptus baxteri, Acacia longifolia, A. sophorae, A. myrtifolia, A. paradoxa, Chrysanthemoides monilifera, Melaleuca armillaris, Leptospermum lanigerum, Leucopogon parviflorus and Rhagodia condoliana. Trees and shrubs were sampled from $0-1.5 \mathrm{~m}$ high, in a $1-\mathrm{m}$ wide band. Leaves were collected from the outside of the canopy, that is, no deeper than $10 \mathrm{~cm}$ from the outside surface of the canopy. Ferns (Pteridium esculentum) were sampled by collecting $100 \mathrm{~g}$ of material from a $1-\mathrm{m}^{2}$ area.

The foliage was not washed, so that both absorbed fluoride and surface contamination could be measured. Samples were oven-dried immediately after collection, for $48 \mathrm{~h}$ at $80^{\circ} \mathrm{C}$. Approximately $2 \mathrm{~g}$ from each weekly sample per site per month was then combined and this composite monthly sample was finely ground using a grinding mill. Four c. 1-g samples were analysed to determine fluoride per $\mathrm{g}$ dry matter using the ion-selective electrode method (Hufschmid et al. 2011). The limit of detection of the laboratory method is $10 \mu \mathrm{gF} / \mathrm{g}$, which is comparable to background levels of fluoride in vegetation from this coastal area (O'Connor and Horsman 1982).

\section{Stomach sample collection}

Twenty stomach samples were obtained for each of the three macropodid species over five years, between 2008 and 2013 (Table 1). Samples were collected during all seasons and from both males and females, although our sample for the red-necked wallaby was biased towards males (Table 1). Most samples were collected from culled or road-kill carcasses, and a small number were from euthanised animals or deaths of unknown cause (Table 1). The distribution of vegetation types is heterogenous over the site (Coulson et al. 2000). Stomach samples collection locations for the three macropodid species and the vegetation samples were spread relatively evenly across the site (Fig 1), although the opportunistic sampling of the individuals from each species is likely to reflect their habitat preferences within the study area. For example, kangaroos were collected mainly from farmland/pasture areas and wallabies mainly from heathland/grassland/scrubland habitats (Table 1).

Contents were removed from the pyloric region of the stomach, which contains fewer parasitic nematodes, at post mortem. Samples were frozen at $-20^{\circ} \mathrm{C}$, then later defrosted and stored in $70 \%$ 
ethanol. This work was conducted with the University of Melbourne Animal Ethics approval \#1011738.3 and Department of Sustainability and Environment research (\#10005596) and management (\#10005418) permits.

\section{Microhistological diet analysis}

Stomach samples were prepared using standard microhistological techniques (Norbury 1988), whereby 10-mL portions of each sample were digested in $4 \%$ sodium hypochlorite (White KingTM, NSW, Australia) for $3 \mathrm{~h}$. To determine the relative area of categories of plant epidermal fragments, point quadrat analysis (Norbury 1988) was used. For each sample, 400 fragments were identified at two levels: 1) broad taxonomic (monocotyledons [monocots], eudicotyledons [dicots], pteridophyta, or bryophyta); 2) functional group (forbs/climbers, shrubs/trees, ferns, grasses, non-graminoid monocots [rushes/sedges/other], mosses, or succulents). The presence of plant reproductive material (fruit/flower/seed/seed pod) in samples was recorded.

Identification of plant epidermal fragments using microhistological diet analysis typically involves preparation of a site-specific microhistological reference herbarium, which provides the basis for identifying plant fragments in herbivore diets (e.g., Davis et al. 2008). However, identification of plant epidermal fragments to plant functional group level was considered adequate to meet the aims of this study. Identification of fragments to this level was possible based on published descriptions of plant epidermal diagnostic features (e.g. differences in cell shape, size, orientation and walls, trichomes, stomata and staining) (Metcalfe and Chalk 1950; Storr 1961; Ellis et al. 1977; Mallett and Cooke 1986), coupled with microhistological reference material prepared for diet analysis studies at other sites (Davis et al. 2008; Forsyth and Davis 2011; Green et al. 2013; Green et al. 2014b; Green et al. 2014a), which included all plant functional groups present at the study site. Plant epidermal fragments could confidently be distinguished at the level of broad taxonomic group. The majority of plant epidermal fragment identifications to the level of plant functional group were also made with certainty based on distinctive epidermal features diagnostic of particular groups. However, some overlap in epidermal diagnostic features occurs between particular functional groups, introducing some uncertainty for a small proportion $(<5 \%)$ of fragments.

\section{Statistical analysis}

To examine variation in foliar fluoride accumulation between plant groups fluoride levels measured during summer and winter 2013 for grasses/forbs, shrubs/trees and ferns were compared using a linear model (LM) in the statistical software environment R (R Core Team 2013, http://www.r-project.org/). The relationship between foliar fluoride level and distance from the smelter between plant groups was also compared using a LM. To examine variation in distance from the smelter between species sampling locations, the location of collection of each stomach sample was compared to the central emission point, using a LM. Residuals for linear models were plotted against the corresponding fitted values to check for distributional problems, and applied square root or logarithm transformations to 
improve residual distributions when necessary. For all analyses, variables were log2-transformed to satisfy model assumptions and enhance interpretation, and a level of significance of $\alpha=0.05$ was used.

To examine macropodid diets two levels of classification were constructed, each of which contained $>2$ categories into which we assigned identified plants: 1) broad taxonomic (monocots, dicots, pteridophyta, or bryophyta); 2) functional group (forbs/climbers, shrubs/trees, ferns, grasses, nongraminoid monocots [rushes/sedges/other], mosses, or succulents). These categories were constructed to allow classification of the diet of each species according to Hansen (1985) and Hofmann and Stewart (1972), and to match as closely as possible the vegetation groups used to sample fluoride deposition/absorption, although exact matching was not possible due to difficulties in differentiating some plant groups microhistologically, for example, climbers. Data from each subsample used in microhistological analysis were pooled to give a total of 400 fragments identified per sample (Norbury 1988), and based analyses on the proportion of plant epidermal fragments identified within categories of interest per stomach sample.

Based on the results of microhistological diet analysis, each macropodid species was classified according to feeding type following Hansen et al. (1985) as: 1) grazers (>50\% monocots) or 2) browsers ( $>50 \%$ dicots). Because this simple division of 'grazer' versus 'browser' may be inadequate to classify herbivore feeding types (Hofmann and Stewart 1972), feeding type (sensu Hofmann and Stewart 1972) of each macropodid species was also classified as 1) bulk and roughage feeders (grazers) that select diets containing $<25 \%$ browse; 2) concentrate selectors (browsers) that select diets containing at least $75 \%$ fruits, dicot foliage, and tree and shrub stems and foliage; or 3) intermediate or mixed feeders that select both grasses and browses (herbaceous and woody dicots such as forbs, shrub leaves and stems; Hofmann and Stewart 1972).

To examine interspecific variation in diet the proportion of fragments identified in each category of level 2 between species was compared using one-factor ANOVA with post hoc Tukey's tests. The functional groups succulent, moss or fern were not compared due to their infrequent occurrence in samples. To further examine the extent of interspecific variation in diet, and to determine which pairs of species had diets that were most similar, overlap in resource use was measured between herbivore species we used Horn's index of niche overlap (Horn 1966):

$$
R_{o}=\frac{\sum\left(p_{i j}+p_{i k}\right) \log \left(p_{i j}+p_{i k}\right)-\sum p_{i j} \log p_{i j}-\sum p_{i k} \log p_{i k}}{2 \log 2}
$$

where $\quad R_{o}=$ Horn's index of overlap for species $j$ and $k$

$P_{i j}=$ Proportion resource $i$ is of the total resources utilised by species $j$

$P_{i k}=$ Proportion resource $i$ is of the total resources utilised by species $k$

Calculations of diet overlap were based on the proportion of fragments identified in samples of each species from each plant functional group. A value of zero for Horn's index of niche overlap indicates no overlap and a value of one indicates complete overlap (Horn 1966). 
Non-metric multidimensional scaling (NMDS) was used to graphically represent interspecific differences in microhistological estimates of diet. These three-dimensional ordination spaces were based on Bray-Curtis dissimilarity matrices (Clarke 1993) for the proportional composition of fragments of each functional group identified per stomach. Non-metric multidimensional scaling scales objects on the basis of a reduced set of variables derived from the original variables, and these new variables are used as the axes; the actual values of the object scores are arbitrary, so only the relative distances (dissimilarities) between objects are important (Quinn and Keough 2003). The following standardization was applied within species to reduce the influence of abundant groups on the NMDS:

$$
x_{i}^{1}=\frac{x_{i}-x_{i, \min }}{x_{i, \max }-x_{i, \text { min }}} \quad \text { for the } i^{\text {th }} \text { variable, }
$$

where $x$ is the proportion of each plant functional group identified per stomach sample.

\section{Results}

\section{Vegetation fluoride levels}

There were no significant differences in foliar fluoride levels between plant groups (Table 2). However, foliar fluoride levels were significantly higher during summer than winter (Fig 2). Fluoride concentration in all plant groups decreased with distance from the central emission point of the smelter (Table 2).

\section{Macropodid diets}

The diet of the swamp wallaby at the Portland Aluminium smelter site was comprised predominantly of dicot material (mean 69\%; 95\% Confidence Interval (CI), 61-78), primarily shrubs/trees (40\%; 95\% CI, 33-48), followed by forbs/climbers (29\%; 95\% CI, 20-38; Fig 3). Monocot material comprised a smaller proportion of the diet (27\%; 95\% CI, 19-36) and consisted almost entirely of grasses (Fig 4). Ferns were a minor component (3\%; 95\% CI, 0-6) of the diet, and other plant functional groups (i.e., succulents, non-graminoid monocots and mosses) each occurred in trace amounts (<1\%; Fig 4).

The diet of the red-necked wallaby consisted predominantly of dicots (62\%; 95\% CI, 51-73) followed by a moderate proportion (38\%; 95\% CI, 27-49) of monocots (Fig 3). However, forbs/climbers constituted the largest proportion (47\%; 95\% CI, 36-58) of the dicots recorded and the monocot component consisted mainly of grasses $(29 \%$; $95 \%$ CI, 19-39), but also included non-graminoid monocots (9\%; 95\% CI, 4-14; Fig 4). Shrubs/trees were recorded in the diet of red-necked wallabies in intermediate proportions (14\%; 95\% CI, 7-21) and ferns, mosses and succulents were again recorded only in trace amounts $(<1 \%$; Fig 4$)$.

The diet of the eastern grey kangaroo consisted almost entirely (88\%; 95\% CI, 80-95) of monocots (Fig 3), predominantly grasses (85\%; 95\% CI, 77-92; Fig 3). Dicots thus comprised a relatively small proportion (13\%; 95\% CI, 5-20) of the diet (Fig 3), represented almost entirely by forbs/climbers 
(12\%; 95\% CI, 4-19; Fig 4). Other functional groups comprised very small proportions of the diet: shrub/tree 1\% (95\% CI, 1-2), non-graminoid monocots $2 \%$ (95\% CI, 1-4), and moss <1\% (Fig 3). Succulents and ferns were not recorded in the diet of the kangaroo (Fig 4).

Stomach samples of all three macropodid species contained plant reproductive material. Seeds, Poaceae seed head material, and unidentified reproductive material (fruit/flower/seed/seed pod) occurred in $30 \%, 30 \%$ and $15 \%$ of swamp wallaby stomach samples, $10 \%, 45 \%$ and $15 \%$ of rednecked wallaby stomach samples, and $5 \%, 40 \%$, and $10 \%$ of eastern grey kangaroo stomach samples, respectively.

There were a number of significant interspecific differences in the diets of macropodids (Table 3; Fig 4). The proportion of forb/climber material in the diet varied significantly between the three species, being lowest for the eastern grey kangaroo and greatest for the red-necked wallaby. Similarly, the proportion of shrub/tree material identified varied significantly between species, again being lowest for the kangaroo, but in this case being greatest for the swamp wallaby. Eastern grey kangaroo samples contained significantly more grass material than samples from the two wallaby species, which did not differ significantly in proportion of grass (Table 3; Fig 4). However, non-graminoid monocot material did vary between the two wallaby species, comprising a greater proportion of red-necked wallaby diet than swamp wallaby samples, whereas the proportion of non-graminoid material in eastern grey kangaroo samples was intermediate to, and did not differ significantly from, the two wallaby species (Table 3; Fig 4).

Overlap in diet resource use between macropodid species was considerable at the level of plant functional group, particularly between the two wallaby species (Horn's index of diet niche overlap $\left(R_{o}\right)$ $=0.90$ ). Lowest overlap in food resource use occurred between the swamp wallaby and the eastern grey kangaroo $\left(R_{o}=0.70\right)$. Overlap between the red-necked wallaby the eastern grey kangaroos was $R_{o}=$ 0.74. Non-metric multidimensional scaling also suggests overlap in the use of plant functional groups by the three species, and particularly by the two wallaby species (Fig 5). Despite this overlap, there was some differentiation in the diets of the three species with respect to the proportion of different plant functional groups consumed (Fig 5). In particular, eastern grey kangaroo samples clustered together and were separated to some degree from those of the two wallaby species, and although samples of the two wallaby species overlapped extensively, some divergence was evident (Fig 5).

\section{Discussion}

\section{Dietary fluoride exposure}

Dietary niche separation was evident between the three macropodid species with respect to the use of plant functional groups that typically vary in fluoride levels (Doley 1986; Bowen 1988; Weinstein and Davison 2004). However, there were no significant differences in foliar fluoride levels between plant groups. Our results indicate that, at the scale measured in this study, interspecific variation in diet is unlikely to explain variation in fluoride accumulation at aluminium smelter sites. 
In general, diets exhibited by the three macropodid species at the aluminium smelter were similar to those recorded at less anthropogenically modified sites (e.g., Jarman and Phillips 1989; Davis et al. 2008), although some minor shifts along the browser-grazer continuum were evident relative to previous classifications (Sanson 1989). These shifts may reflect altered resource availability at novel industrial sites. In line with classification of the swamp wallaby as a browser (Sanson 1989), this species was a browser at the aluminium smelter site according to the classification of Hansen et al. (1985), but was classified as a mixed feeder following Hofmann and Stewart (1972). The swamp wallaby consumed a large proportion of shrubs/trees and correspondingly lower proportions of forbs and grasses, consistent with estimates of the food consumed by this species at several other sites (Hollis et al. 1986; Wood 2002; Davis et al. 2008; Green et al. 2014b). However, some individuals displayed diets more typical of grazers, consuming up to $60 \%$ grasses. While selection for shrubs and avoidance of grasses has been demonstrated (Wood 2002) in this species, swamp wallabies may increase intake of grasses and forbs seasonally and consume considerable quantities of these food groups at some sites (Harrington 1976; Osawa 1990; Di Stefano and Newell 2008). Spatial and temporal variation in food resource use suggests that the swamp wallaby is a generalist feeder (Hollis et al. 1986). The apparent shift in feeding strategy of the swamp wallaby towards that of a mixed feeder at the aluminium smelter site is likely to reflect alteration of its foraging strategy in response to food quality and availability (Osawa 1990).

The red-necked wallaby has been classified as an intermediate grazer/browser (Sanson 1989). Typically, monocots, primarily grasses, make up a large proportion of its diet, while forbs and shrubs are consumed in smaller proportions (Jarman and Phillips 1989; Sprent and McArthur 2002; Wood 2002). While the red-necked wallaby at the aluminium smelter site was classified as a mixed feeder following Hofmann and Stewart (1972), it was classified as a browser following Hansen et al. (1985). The red-necked wallaby is capable of using browse, for example in woodland (Weir et al. 1995) and alpine habitat (Green et al. 2014b), likely reflecting diet shifts in response to limited availability of grass resources. At the aluminium smelter site, the largest component of the diet was forbs/climbers, though several individuals had diets typical of grazers.

Consistent with previous classification of the eastern grey kangaroo (Sanson 1989), this species was a grazer (sensu Hofmann and Stewart 1972; Hansen et al. 1985) at the aluminium smelter site, consuming primarily grasses in line with studies at numerous other sites (e.g., Taylor 1983; Jarman and Phillips 1989; Davis et al. 2008). On average, forbs/climbers comprised small proportion of the kangaroo diet, although one individual consumed enough forb material to be classified as a browser according to Hansen et al. (1985).

These three diets, ranging from a browser, to an intermediate grazer/browser, to a grazer, suggest that if foliar fluoride levels vary between graze and browse, each species will be exposed to different levels of dietary fluoride, and differences will be most pronounced between the kangaroo and the swamp 
wallaby, whose diets overlapped least. In line with this prediction, the swamp wallaby exhibited lower bone fluoride levels than did the eastern grey kangaroo, which exhibited similar levels to the rednecked wallaby (Death et al. 2015). However, mean foliar fluoride levels on grasses/forbs, the main component of the eastern grey kangaroo and red-necked wallaby were similar to levels on shrubs/trees, the main component of the swamp wallaby diet, indicating that dietary fluoride exposure is similar for the three species. This is supported by observations by Death et al. (2015, unpublished data) in a sample of macropods at this site, which showed that the concentration of fluoride in the stomach contents from these three species did not differ. However, aspects of interspecific variation in diet may contribute to differential exposure to fluoride. For example the two wallaby species, and in particular the swamp wallaby, consumed fern material whereas the kangaroo did not. Given that fluoride concentrations are lower in stems, roots and reproductive structures than in leaves (Doley 1986; Salatas et al. 2009), greater consumption of seeds and unidentified reproductive material by the two wallaby species compared to the kangaroo may result in lower dietary fluoride exposure in wallabies (Salatas et al. 2009). Interspecific differences in fluoride accumulation factors are likely to also be influenced by factors such as home range, feeding behaviour, health status, rate of absorption, and timing of exposure are likely to influence (Kierdorf et al. 1993; Vikøren and Stuve 1996; Vikøren et al. 1996; Kierdorf et al. 2012).

Further, foliar fluoride uptake and accumulation vary between plant species (Murray 1981; O'Connor and Horsman 1982; Divan Jr et al. 2008), related to plant properties such as the ratio of leaf surface area to dry weight, leaf arrangement and fluoride conductance (Murray 1981; Doley 1986). For example, Acacia species with bipinnate, compound leaves and small, thin leaflets have higher surface area to dry weight than species with thicker phyllodes, influencing foliar fluoride concentrations. Despite the lack of significant differences in foliar fluoride levels between plant groups at a broad scale, variation between plant species, genera or families may explain inconsistencies between relative foliar fluoride concentrations measured at the aluminium smelter site, and generalisations regarding expected relative levels (Doley 1986). For example, we recorded high levels of fluoride in Melaleuca armillaris across seasons at one sampling site, which was relatively far from the smelter, where forage fluoride levels were consistently low. Bowen (1988) recorded greater fluoride accumulation for some understorey shrubs than for some overstorey tree species, and high variability occurs in pasture fluoride levels (Doley 1986), reflecting variation in species composition (Davison et al. 1979). While we do not have plant species-specific data on fluoride accumulation, nor diet information at this resolution, the suites of plant families consumed by the three macropodid species vary, providing evidence that fluoride exposure levels are likely to differ between macropodid species. Dietary fluoride exposure may need to be assessed at a finer taxonomic scale than plant functional group, or extended to all functional groups consumed by herbivores at smelter sites.

Furthermore, diet and/or vegetation fluoride levels may not have been measured at the appropriate spatial scale to link these to dietary fluoride exposure. While individuals of each macropodid species were sampled from across the site, as were foliar fluoride levels, the vegetation was heterogenous and 
some clumping of sampling in particular habitat types occurred (Table 1), likely representing interspecific differences in habitat preference. Differences in habitat use may result in different species having different levels of exposure to dietary fluoride even when using the same food types. Specifically, animals foraging primarily beneath the canopy may have lower exposure than animals that forage in the open. The swamp wallaby prefers habitat with dense cover (Merchant 2008; Di Stefano et al. 2009), while the eastern grey kangaroo favours open habitat (Hill 1978) and the rednecked wallaby uses grassland and open forest mosaics (Southwell 1987). The foliar fluoride sampling strategy used may have resulted in sampling of grasses/forbs, shrubs/trees and ferns from areas where they were subject to similar levels of shelter. To assess dietary fluoride exposure of herbivores, it may be necessary to estimate fluoride accumulation on vegetation within the foraging range of each species, or even each individual. Further, fluoride levels vary within individual plants according to leaf position and age, and even within particular parts of the leaf (Doley 1986). Sampling biases may also occurr in the way in which individual plants are sampled. In particular, closely-packed shrub leaves can reduce fluoride accumulation (Doley 1986) and if the swamp wallaby browses shrub foliage deeper than the outer 10-cm layer in which foliar fluoride levels were sampled during this study, dietary fluoride exposure for this species may have been overestimated.

There was significant seasonal variation in foliar fluoride concentrations, as has been reported previously (e.g., Murray 1981; O'Connor and Horsman 1982; Bowen 1988), likely related to effects of weather on plume dispersal, precipitation, leaf age and rate of turnover, morphology and stage of development or senescence (MacLean et al. 1969; Davison et al. 1973), environmental conditions, and plant responses to these conditions (Mitchell et al. 1981). For example, older, dry grass is higher in fluoride than young grass, as new growth has some physical protection at the base of the plant and young leaves do not have functional stomata through which gaseous fluoride can diffuse (Doley 1986). In particular, fluoride levels were relatively high during summer, indicating that herbivores experienced relatively high levels of exposure at this time. Wind direction changes markedly with season and at this site, predominantly on-shore summer winds deposit emissions over the buffer zone vegetation, whereas off-shore winds in winter disperse most of the emissions over the ocean (Kinhill 1980). As herbivore diets can change seasonally (e.g., Osawa 1990) studies that examine average diets across seasons, may not accurately assess dietary fluoride exposure.

\section{Implications for management}

Vegetation buffer zones at industrial sites function as sinks for pollutants (Murray 1982). Hence industrial zones often have degraded landscapes with low biodiversity. At aluminium smelters, these zones experience higher concentrations of fluoride so may be impacted by its phytotoxic effects (Weinstein and Davison 2004). Interspecific variation in plant tolerance to fluorides may result in changes in plant community composition and structure as sensitive tree and shrub species are replaced by tolerant species (Murray 1981; Weinstein and Davison 2003). However, with appropriate management, these zones can provide novel habitat for biodiversity conservation as seen at Portland Aluminium (Coulson et al. 2000). The challenge is to manage these zones to encourage biodiversity 
while minimising the risk of fluorosis. Our study demonstrates the potential for unexpected shifts in the diets of resident herbivorous wildlife to occur in such a novel environment. Site-specific information on herbivore diets, coupled with local data on foliar fluoride accumulation, has the potential to enable managers to mitigate harmful impacts of fluoride on wildlife populations.

Fluoride accumulation on vegetation generally decreases exponentially with the distance from a point emission source (Divan Jr et al. 2008). Quantification of dietary fluoride levels with respect to distance from the emission source and recommended limits for dietary fluoride exposure (Suttie 1980; Arnesen 1997) may enable managers to determine an appropriate distance within which to reduce foraging. Our sampling coverage and intensity for estimation of diet and foliar fluoride levels was not adequate to examine spatial variation in dietary fluoride exposure, and our results were limited by uncertainty regarding the foraging range of the animals sampled. This is likely to be important because annual mean fluoride levels on both grasses/forbs and shrubs/trees exceeded recommended limits for fluoride content in pasture for livestock $(<30-40 \mu \mathrm{gF} / \mathrm{g}$, Suttie 1969; USEPA 1979; USEPA 1993; Arnesen 1997), yet the vegetation sampling points in close proximity $(<500 \mathrm{~m})$ to the smelter, where there is limited wildlife activity due to fencing and roads, heavily influenced the mean, and the median annual fluoride content was below recommended limits $(<25 \mu \mathrm{gF} / \mathrm{g})$.

To accurately predict the risks posed by dietary exposure to industrial pollution, monitoring of foliar fluoride levels at aluminium smelter sites should include all major plant functional groups consumed by herbivores. Herbivore diets and foliar fluoride accumulation should be estimated at the same spatial and temporal scale, and this scale should reflect interspecific differences in habitat use. These variables could also be monitored at finer resolution such as at the level of plant species, because broader grouping of plants may be inappropriate if herbivores are selecting for particular plant species that differ markedly in fluoride accumulation. Moreover, given seasonal variation in foliar fluoride levels, year round analysis of vegetation fluoride levels at this resolution may be required. More comprehensive information regarding foliar fluoride levels, coupled with information about herbivore diets may allow managers to predict species-specific fluoride exposure risks and manage wildlife within buffer zones accordingly to mitigate the impacts of fluoride. 


\section{References}

Arnesen AKM (1997) Availability of fluoride to plants grown in contaminated soils. Plant Soil 191:1325

Boivin G, Chavassieux P, Chapuy MC, Baud CA, Meunier PJ (1990) Skeletal fluorosis: histomorphometric findings. J Bone and Miner Res 5:S185-S189

Boulton IC, Cooke JA, Johnson MS (1994) Fluoride accumulation and toxicity in wild small mammals. Environ Pollut 85:161-167

Bowen SE (1988) Spatial and temporal patterns in the fluoride content of vegetation around 2 aluminum smelters in the Hunter Valley, New-South-Wales. Sci Total Environ 68:97-111

Carlson KJ, Jashashvili T, Houghton K, Westaway MC, Patel BA (2013) Joint loads in marsupial ankles reflect habitual bipedalism versus quadrupedalism. PLoS One 8:1-9

Clarke KR (1993) Non-parametric multivariate analyses of changes in community structure. Aust J Ecol 18:117-143

Coulson G, Hill J, McKenzie J, Walters B (2000) The Smelter in the Park: managing wildlife for biodiversity In: Craig JL, Mitchell N, Saunders DA (eds) Nature Conservation 5: Nature Conservation in Production Environments: Managing the Matrix. Surrey Beatty \& Sons, Chipping Norton, N.S.W., pp 360-371

Crompton AW, Owerkowicz T, Skinner J (2010) Masticatory motor pattern in the koala (Phascolarctos cinereus): A comparison of jaw movements in marsupial and placental herbivores. J Exp Zool Part A A: Ecological Genetics and Physiology 313 A:564-578

Davis NE, Coulson G, Forsyth DM (2008) Diets of native and introduced mammalian herbivores in shrub-encroached grassy woodland, south-eastern Australia. Wildlife Res 35:684-694

Davison AW (1983) Uptake, transport and accumulation of soil and airborne fluorides by vegetation In: Shupe JL, Peterson HB, Leone MC (eds) Fluorides: Effects on vegetation, animals and humans. Paragon Press, Salt Lake City, pp 61 - 82

Davison AW, Blakemore J, Craggs C (1979) The fluoride content of forage as an environmental quality standard for the protection of livestock. Environ Pollut (1970) 20:279-296

Davison AW, Rand AW, Betts WE (1973) Measurement of atmospheric fluoride concentrations in urban areas. Environ Pollut 5:23-33

De Lange H, De Lange J, Lahr JJCV, der Pol Y, Wessels J, Faber (2009) Ecological vulnerability in wildlife: An expert judgment and multicriteria analysis tool using ecological traits to assess relative impact of pollutants. Environ Toxicol Chem 28:2233-2240

Death CE, Coulson G, Kierdorf U, Kierford H, Morris W, Hufschmid J (2015) Dental fluorosis and skeletal fluoride content as biomarkers of excess fluoride exposure in marsupials. Sci Total Environ533:528-541

Di Stefano J, Newell GR (2008) Diet selection by the swamp wallaby (Wallabia bicolor): feeding strategies under conditions of changed food availability. J Mammal 89:1540-1549

Di Stefano J, York A, Swan M, Greenfield A, Coulson G (2009) Habitat selection by the swamp wallaby (Wallabia bicolor) in relation to diel period, food and shelter. Austral Ecol 34:143155

Divan Jr AM, Oliva MA, Ferreira FA (2008) Dispersal pattern of airborne emissions from an aluminium smelter in Ouro Preto, Brazil, as expressed by foliar fluoride accumulation in eight plant species. Ecol Indic 8:454-461

Doley D (1986) Plant-fluoride relationships. Bookbuilders Ltd, Hong Kong

Ellis BA, Russell EM, Dawson TJ, Harrop CJF (1977) Seasonal changes in the diet preferences of freeranging red kangaroos, euros and sheep in Western NSW. Aust Wildlife Res 4:127-144

Everett ET (2011) Fluoride's effects on the formation of teeth and bones, and the influence of genetics. J Dental Res 90:552-560

Fejerskov O, Thylstrup A, Larsen MJ (1977) Clinical and structural features and possible pathogenic mechanisms of dental fluorosis. Scand J Dent Res 85:510-534

Forsyth DM, Davis NE (2011) Diets of non-native sambar deer in Australia estimated by macroscopic versus microhistological rumen analysis J Wildlife Manage75:1488-1497

Garrott RA, Eberhardt LL, Otton JK, White PJ, Chaffee MA (2002) A geochemical trophic cascade in Yellowstone's geothermal environments. Ecosystems 5:659-666

Gleeson J, Gleeson D (2012) Reducing the impacts of development on wildlife. CSIRO Publishing, Melbourne 
Green K, Davis NE, Robinson WA (2014a) Diet of the Broad-toothed Rat Mastacomys fuscus (Rodentia:Muridae) in the alpine zone of the Snowy Mountains, Australia. Australian Zoologist 37:225-233

Green K, Davis NE, Robinson WA (2014b) Does diet constrain the occupation of high elevations by macropods? A comparison between Macropus rufogriseus and Wallabia bicolor. Australian Mammalogy 36:219-228

Green K, Davis NE, Robinson WA, McAuliffe J, Good RB (2013) Diet selection by European hares (Lepus europaeus) in the alpine zone of the Snowy Mountains, Australia. Eur J Wildlife Res 59:693-703

Hansen RM, Mugambi MM, Bauni SM (1985) Diets and trophic ranking of ungulates in the Northern Serengeti. J Wildlife Manage 49:823-829

Harrington J (1976) The diet of the swamp wallaby, Wallabia bicolor, at Diamond Flat, New South Wales. PhD, University of New England

Hill GJE (1978) Preliminary assessment of defecation patterns for the eastern grey kangaroo (Macropus giganteus). Australian Zoologist 19:291-300

Hofmann RR, Stewart DRM (1972) Grazer or browser: A classification based on the stomach-structure and feeding habits of East African ruminants. Mammalia 36:226-240

Hollis CJ, Robertshaw JD, Harden RH (1986) Ecology of the swamp wallaby (Wallabia bicolor) in northeastern New South Wales .1. Diet. Aust Wildlife Res 13:355-365

Horn HS (1966) Measurement of "overlap" in comparative ecological studies. Am Nat 100:419-424

Hufschmid J, Beveridge I, Coulson G, Gould J (2011) Bone fluoride concentrations of eastern grey kangaroos (Macropus giganteus) resident near an aluminium smelter in south-eastern Australia. Ecotoxicology 20:1378-1387

Hufschmid J, Beveridge I, Coulson G, Walker G, Shen P, Reynolds E, Charles J (2015) Skeletal pathology of eastern grey kangaroos (Macropus giganteus) exposed to high environmental fluoride levels in south-eastern Australia. Journal of Comparative Pathology 153:167-184.

Jarman PJ, Phillips CM (1989) Diets in a community of macropod species In: Grigg G, Jarman P, Hume I (eds) Kangaroos, Wallabies and Rat-Kangaroos, vol 1. Surrey Beatty and Sons, Chipping Norton, New South Wales, pp 143-149

Kierdorf H, Kierdorf U, Sedlacek F, Erdelen M (1996a) Mandibular bone fluoride levels and occurrence of fluoride induced dental lesions in populations of wild red deer (Cervus elaphus) from central Europe. Environ Pollut 93:75-81

Kierdorf U, Bahelkova P, Sedlacek F, Kierdorf H (2012) Pronounced reduction of fluoride exposure in free-ranging deer in North Bohemia (Czech Republic) as indicated by the biomarkers skeletal fluoride content and dental fluorosis. Sci Total Environ 414:686-695

Kierdorf U, Kierdorf H (1999) Dental fluorosis in wild deer: its use as a biomarker of increased fluoride exposure. Environ Monit and Assess 57:265-275

Kierdorf U, Kierdorf H, Fejerskov O (1993) Fluoride-induced developmental changes in enamel and dentine of European roe deer (Capreolus capreolus L.) as a result of environmental pollution. Arch Oral Bio 38:1071-1081

Kierdorf U, Kierdorf H, Sedlacek F, Fejerskov O (1996b) Structural changes in fluorosed dental enamel of red deer (Cervus elaphus L.) from a region with severe environmental pollution by fluorides. J Anat 188:183-195

Kinhill (1980) Alcoa Portland Aluminium Smelter. Environmental Effects Statement and Draft Environmental Impact Statement. Melbourne, Australia

Lundholm JT, Richardson PJ (2010) Habitat analogues for reconciliation ecology in urban and industrial environments. J Appl Ecol 47:966-975

MacLean DC, Schneider RE, Weinstein LH (1969) Accumulation of fluoride by forage crops. Contrib Boyce Thompson Inst PI Res 7:165-166

Mallett KJ, Cooke BD (1986) The ecology of the common wombat in South Australia. Nature Conservation Society of South Australia, Adelaide

McBee K, Bickham JW (1990) Mammals as bioindicators of environmental toxicity In: Genoways HH (ed) Current Mammalogy, vol 2. Plenum Press, New York and London, pp 37-82

Merchant JC (2008) Swamp wallaby (Wallabia bicolor) In: Van Dyck S, Strahan R (eds) The Mammals of Australia. 3rd Edition edn. Reed New Holland, Sydney, pp 404-405

Metcalfe CR, Chalk L (1950) Anatomy of the dicotyledons. Clarendon Press, Oxford

Mitchell AD, Dowling BJ, Scheltema JH (1981) The effects of gaseous fluoride on Australian vegetation .1. Results of an 8 year sampling program in the vicinity of an aluminum smelter. Clean Air 15:28-32 
Murphy CE, Sinclair TR, Knoerr KR (1977) An assessment of the use of forests as sinks for the removal of atmospheric sulphur dioxide. J Environ Qual 6:388-396

Murray F (1981) Effects of fluorides on plant communities around an aluminium smelter. Environ Pollut A, Ecological and Biological 24:45-56

Murray F (1982) Ecosystems as sinks for atmospheric fluoride In: Fluoride emissions: their monitoring and effects on vegetation and ecosystems. Academic Press Australia, Sydney, Australia, pp 191-205

Narayan D, Agrawal M, Pandey J, Singh J (1994) Changes in vegetation characteristics downwind of an aluminium factory in India. Ann Bot 73:557-565

Newman J, Newman RK, Schreiber (1988) Air pollution and wildlife toxicology: An overlooked problem. Environ Toxicol Chem7:381-390

Norbury GL (1988) Microscopic analysis of herbivore diets - a problem and a solution. Australian Wildlife Res 15:51-57

NPI (2014) National Pollutant Inventory, Fluoride compounds from all sources , 2013/2014 data within Australia. http://www.npi.gov.au/npidata/action/load/individual-facilitydetail/criteria/state/null/year/2014/jurisdiction-facility/00004729. Accessed June 30th 2015

O'Connor JA, Horsman DC (1982) Fluoride levels in vegetation and ambient air in the Portland (Victoria) area In: Murray F (ed) Fluoride Emissions: Their monitoring and effects on vegetation and ecosystems. Academic Press, Sydney, Australia, pp 77-92

Osawa R (1990) Feeding strategies of the swamp wallaby, Wallabia bicolor, on North Stradbroke Island, Queensland. I: Composition of diets. Aust Wildlife Res 17:615-621

Palamara J, Phakey PP, Rachinger WA, Sanson GD, Orams HJ (1984) On the nature of the opaque and translucent enamel regions of some macropodinae (Macropus giganteus, Wallabia bicolor and Peradorcas concinna). Cell Tissue Res 238:329-337

Quinn GP, Keough MJ (2003) Experimental design and data analysis for biologists. Cambridge University Press, Cambridge

Ross PS, De Swart RL, Van Loveren H, Osterhaus ADME, Vos JG (1996) The immunotoxicity of environmental contaminants to marine wildlife: A review. Annual Review of Fish Diseases 6:151-165

Salatas JH, Booth PN, Gard NW, O'Boyle RA, Mackay CE (2009) Risk assessment as a decisionmaking tool for treatment of emissions at a new aluminum smelter in Iceland: 3 . Ecological assessment. Human and Ecological Risk Assessment 15:469-502

Sanson GD (1989) Morphological adaptations of teeth to diets and feeding in the Macropodoidea In: Grigg G, Jarman P, Hume I (eds) Kangaroos, Wallabies and Rat-Kangaroos, vol 1. Surrey Beatty and Sons, Chipping Norton, New South Wales, pp 151 - 168

Schultz M, Kierdorf U, Sedlacek F, Kierdorf H (1998) Pathological bone changes in the mandibles of wild red deer (Cervus elaphus L.) exposed to high environmental levels of fluoride. J Anat $193: 431-442$

Shupe JL (1980) Clinicopathologic features of fluoride toxicosis in cattle. J Anim Sci 51:746-758

Shupe JL, Olson AE, Peterson HB, Low JB (1984) Fluoride toxicosis in wild ungulates. J AmVet Med 185:1295-1300

Smith WH (1974) Air pollution-Effects on the structure and function of the temperate forest ecosystem. Environ Pollut 6:111-129

Southwell C (1987) Activity pattern of the eastern grey-kangaroo, Macropus giganteus. Mammalia 51:211-223

Sprent JA, McArthur C (2002) Diet and diet selection of two species in the macropodid browser-grazer continuum: do they eat what they 'should'? Aust J Zool 50:183-192

Storr GM (1961) Microscopic analysis of faeces, a technique for ascertaining the diet of herbivorous mammals. A J Biol Sci 14:157-165

Suttie JS, Dickie R, Clay AB, Nielsen P, Mahan WE, Baumann DP, Hamilton RJ (1987) Effects of fluoride emissions from a modern primary aluminum smelter on a local population of whitetailed deer (Odocoileus virginianus). J Wildlife Dis 23:135-143

Suttie JW (1969) Fluoride content of commercial dairy concentrates and alfalfa forage. J Ag Food Chem 17:1350-1352

Suttie JW (1980) Nutritional aspects of fluoride toxicosis. J Anim Sci51:759-766

Taylor R (1983) The diet of the eastern grey kangaroo and wallaroo in areas of improved and native pasture in the New England tablelands. Wildlife Res 10:203-211

USEPA (1979) Primary Aluminium Draft Guidelines for control of fluoride emissions from existing primary aluminium plants. United States Environmental Protection Agency, Office of air quality planning and standards, North Carolina, USA 
USEPA (1993) Wildlife exposure factors handbook vol 1. Washington D.C.

Vikøren T, Stuve G (1996) Fluoride exposure in cervids inhabiting areas adjacent to aluminum smelters in Norway. II. Fluorosis. J Wildlife Dis 32:181-189

Vikøren T, Stuve G, Frøslie A (1996) Fluoride exposure in cervids inhabiting areas adjacent to aluminum smelters in Norway. I. Residue levels. Journal of Wildlife Diseases 32:169-180

Walton KC (1984) Fluoride in fox bone near an aluminium reduction plant in Anglesey, Wales, and elsewhere in the United Kingdom. Environmental Pollution, B 7:273-280

Weatherell JA, Weidmann SM (1959) The skeletal changes of chronic experimental fluorosis. The Journal of Pathology and Bacteriology 78:233-241

Weinstein LH, Davison AW (2003) Native plant species suitable as bioindicators and biomonitors for airborne fluoride. Environ Pollut 125:3-11

Weinstein LH, Davison AW (2004) Fluoride in the Environment. CABI Publishing, Oxon, UK

Weir A, McLeod J, Adams CE (1995) The winter diet and parasitic fauna of a population of rednecked wallabies Macropus rufogriseus recently introduced to Scotland. Mammal Review 25:111-116

WHO (2000) Fluorides - Air Quality Guidelines In. Copenhagen, Denmark, 2000,

Wood MS (2002) Resource partitioning in sympatric populations of red-necked and black wallabies. PhD Thesis, Deakin University 
Table 1: Number of male and females of each macropodid species sampled from each habitat, season, sampling source and distance from central emission point of the Portland Aluminium Smelter, southwest Victoria, between 2008-13.

\begin{tabular}{|c|c|c|c|c|}
\hline \multicolumn{2}{|l|}{ Sample category } & $\begin{array}{c}\text { Eastern grey } \\
\text { kangaroo }\end{array}$ & $\begin{array}{c}\text { Red-necked } \\
\text { wallaby }\end{array}$ & $\begin{array}{l}\text { Swamp } \\
\text { wallaby }\end{array}$ \\
\hline \multirow[t]{2}{*}{ Sex } & Female & 11 & 6 & 7 \\
\hline & Male & 9 & 14 & 13 \\
\hline \multirow[t]{2}{*}{ Habitat } & Farm/pasture & 16 & 8 & 7 \\
\hline & Heathland/grassland/scrubland & 4 & 12 & 13 \\
\hline \multirow[t]{4}{*}{ Season } & Summer & 10 & 7 & 7 \\
\hline & Autumn & 3 & 2 & 5 \\
\hline & Winter & 4 & 8 & 2 \\
\hline & Spring & 3 & 3 & 6 \\
\hline \multirow[t]{2}{*}{ Distance* $^{*}(\mathrm{~m})$} & Mean & 1229 & 1280 & 1308 \\
\hline & $\begin{array}{l}\text { Median } \\
\min , \max \end{array}$ & $\begin{array}{c}1233 \\
782,1731\end{array}$ & $\begin{array}{c}1123 \\
657,2021\end{array}$ & $\begin{array}{c}1154 \\
510,2218\end{array}$ \\
\hline
\end{tabular}

*Sampling distance from smelter was not significantly different among species, (ANOVA): $F(2,37)=$ $0.151, p=0.86$.

Table 2: Linear model predicting ( $\log 2$ transformed) $\mu \mathrm{gF} / \mathrm{g}$ dry matter in three plant groups (grasses/forbs, shrub/trees and ferns, with grasses/forbs as baseline) by season (summer or winter, with summer as baseline) and distance from smelter (m) at 19 sites in 2013 at the Portland Aluminium Smelter, south-west Victoria, $\mathrm{SE}=$ standard error, $\mathrm{CI}=$ confidence interval, values in bold are significant effects.

\begin{tabular}{|c|c|c|c|c|}
\hline & $\begin{array}{c}\text { Coefficients } \\
(\beta)\end{array}$ & $\begin{array}{c}\text { SE of } \\
\text { coefficient } \\
(\beta)\end{array}$ & $p$-value & $95 \% \mathrm{Cl}$ \\
\hline Intercept & 7.017 & 0.543 & & $5.94 ; 8.11$ \\
\hline Season (winter) & -1.381 & 0.305 & $<0.001$ & $-1.99,-0.78$ \\
\hline Distance & -0.002 & 0.001 & $<0.001$ & $-0.003,-0.001$ \\
\hline \multicolumn{5}{|l|}{ Plant group: } \\
\hline Grasses/forbs $^{a}$ & 0 & - & & \\
\hline Ferns $^{a}$ & -0.699 & 0.486 & 0.154 & $-1.67,0.267$ \\
\hline Shrubs/trees ${ }^{a}$ & 0.048 & 0.326 & 0.882 & $-0.59 ; 0.69$ \\
\hline
\end{tabular}


Table 3: Results of one-factor ANOVAs comparing the mean proportion (square-root transformed when necessary) of each of the Broad Taxonomic and Functional Group category recorded in stomach samples collected from swamp wallaby (Wallabia bicolor; SW: $n=20$ ), red-necked wallaby (Notamacropus rufogriseus; RN: $n=20$ ) and eastern grey kangaroo (Macropus giganteus; EGK: $n=$ 20) between 2008-13 from Portland Aluminium Smelter, south-west Victoria. $p$ values in bold are significant effects. Where applicable, results for pair-wise comparisons using Tukey's post-hoc analysis are included.

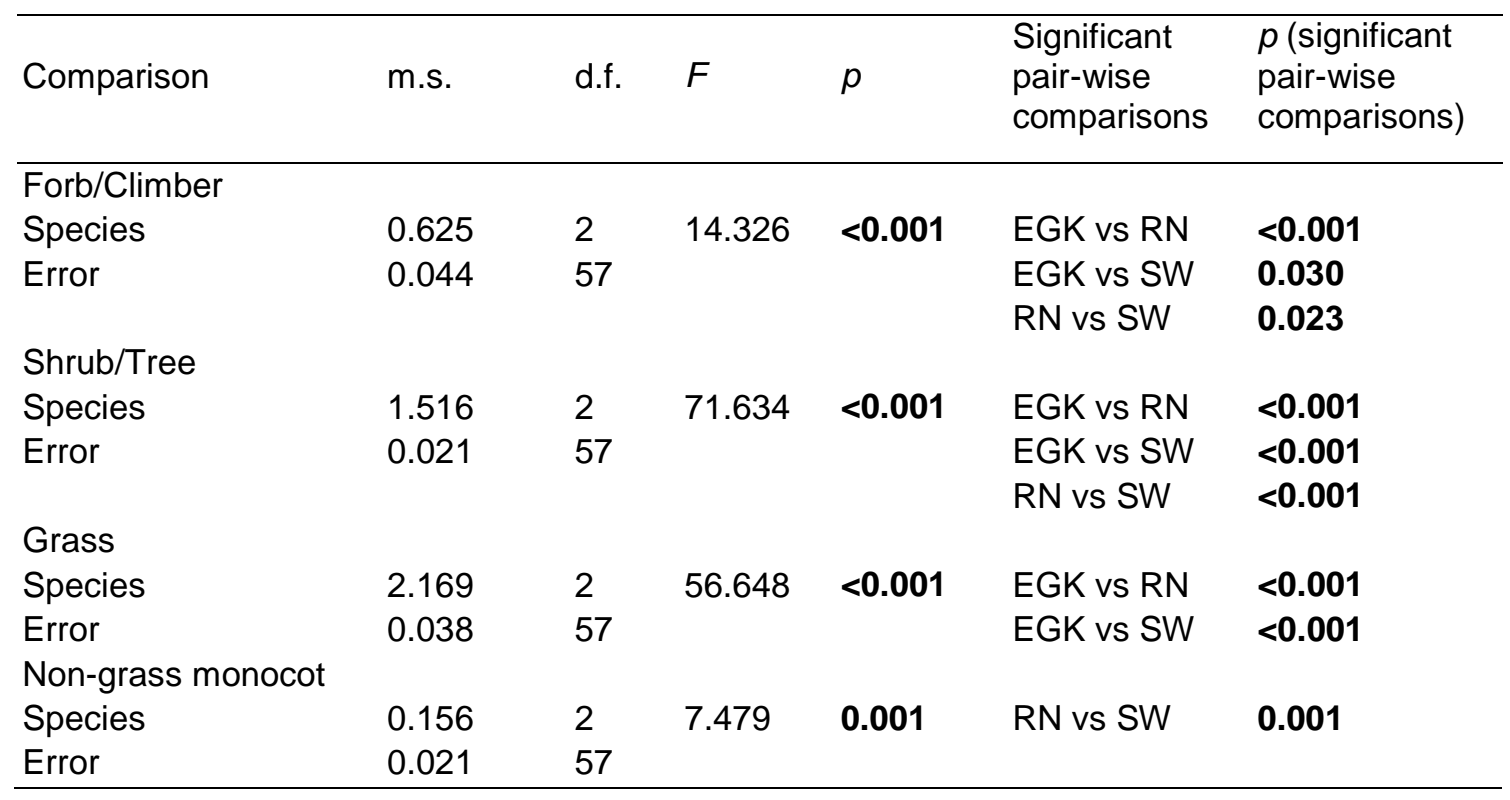




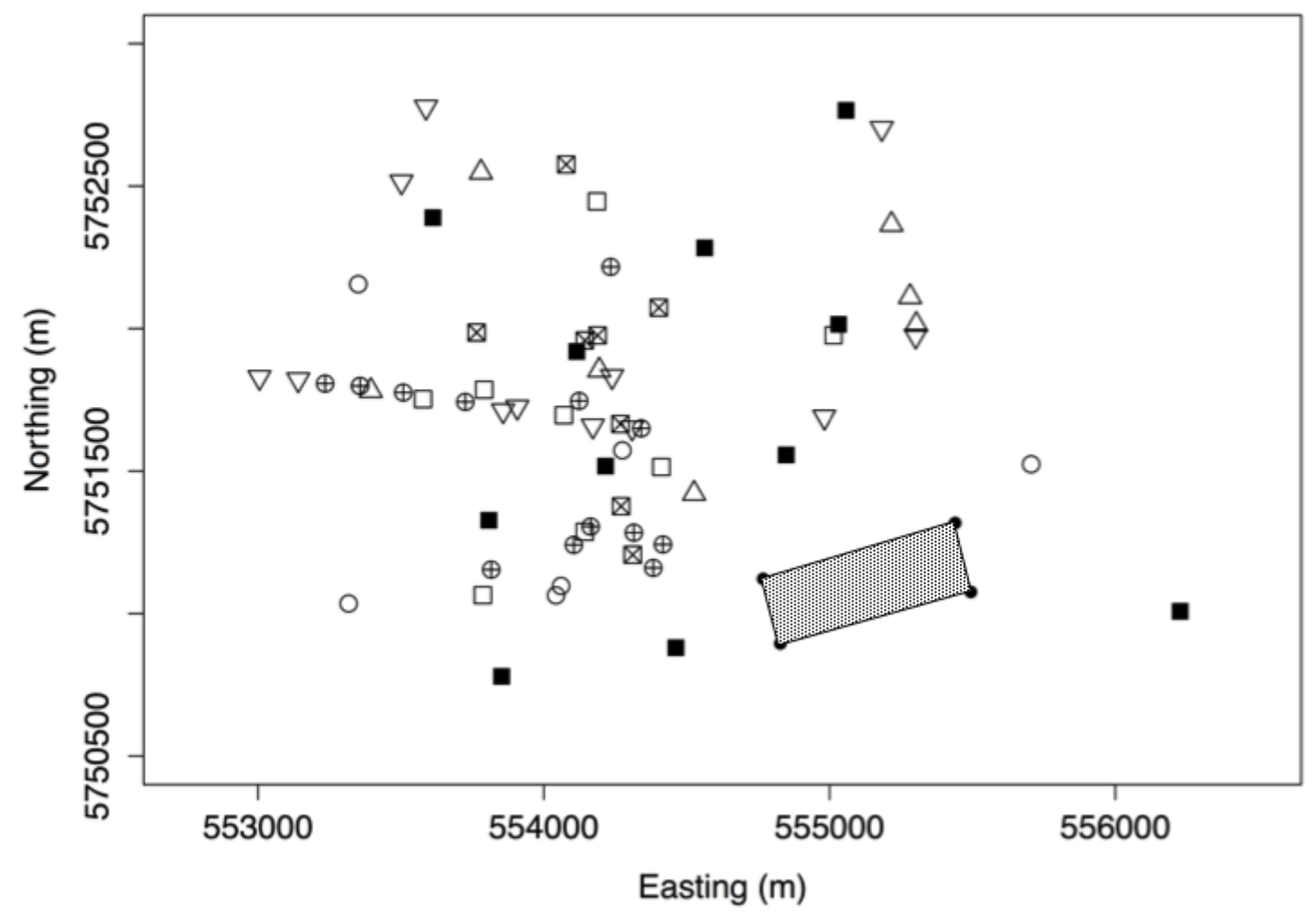

Fig. 1 Locations of stomach content sample collection from eastern grey kangaroos (Macropus giganteus; male $囚 n=9$; female $\square n=11$ ), red-necked wallabies (Notamacropus rufogriseus; male $\otimes, n=14$; female , $n=6$ ) and swamp wallabies (Wallabia bicolor; male $\nabla, n=13$; female $\Delta, n=7$ ), and vegetation sample (ם) collection, at the Portland Aluminium Smelter (shaded rectangle) in Victoria, Australia, between 2008 and 2013 


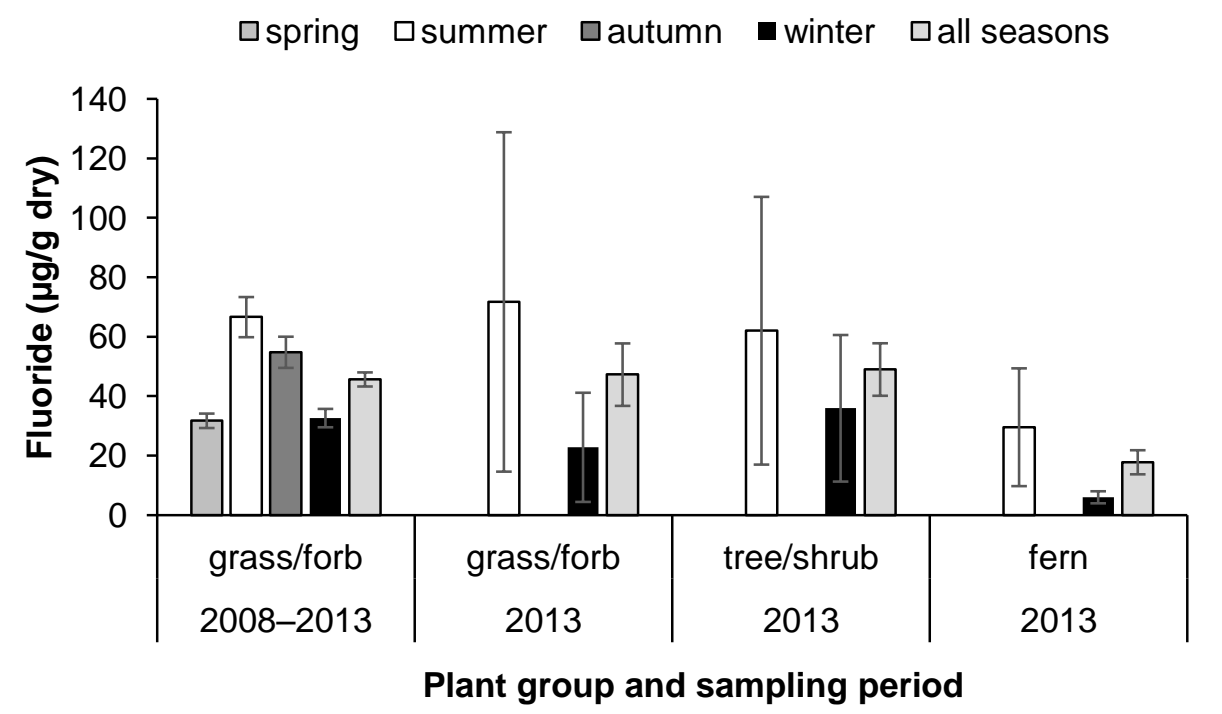

Fig. 2 Mean (with 95\% confidence intervals) fluoride levels measured monthly on grass/forb during summer, autumn, winter, spring and across all seasons ( $n=342$ per season) between 2008-2013, and during summer and winter 2013 on grass/forb ( $n=22$ per season), tree/shrub ( $n=20$ per season) and fern $(n=6$ per season $)$ 


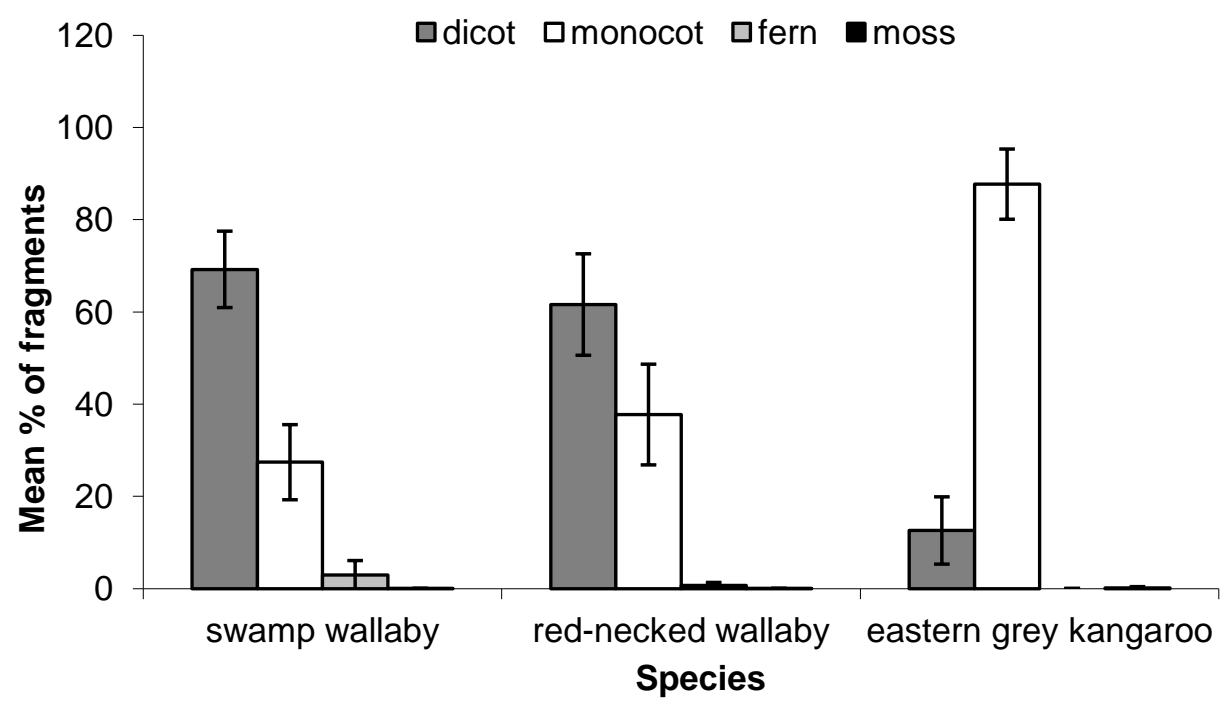

Fig. 3 Mean $\%$ of fragments (with $95 \%$ confidence limits) identified using microhistological techniques from each of the broad taxonomic groups, dicots, monocots and ferns, in swamp wallaby (Wallabia bicolor; $n=20$ ), red-necked wallaby (Notamacropus rufogriseus; $n=20$ ) and eastern grey kangaroo (Macropus giganteus; $n=20$ ) stomach samples collected between 2008-13 from Portland Aluminium Smelter, south-west Victoria 


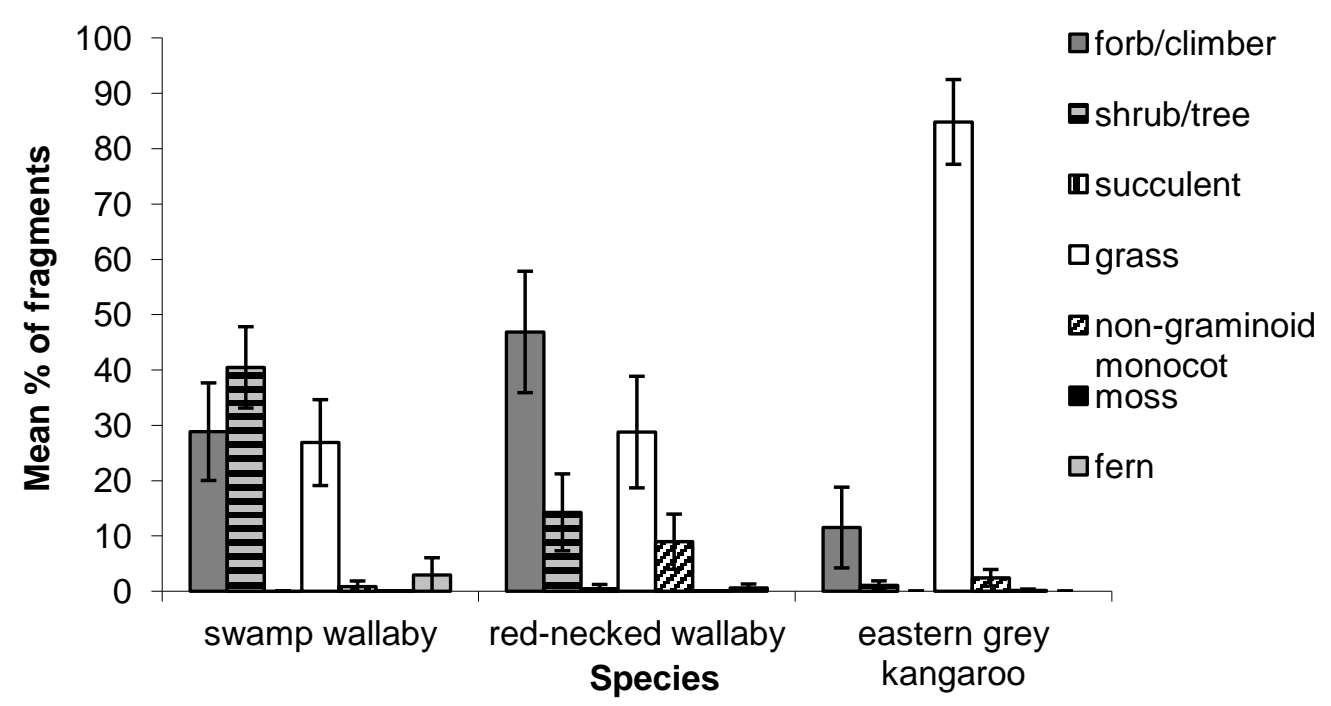

Fig. 4 Mean $\%$ of fragments (with 95\% confidence limits) identified using microhistological techniques from each plant functional group (forb/climber, shrub/tree, succulent, grass, non-grass monocot, moss, fern) recorded in swamp wallaby (Wallabia bicolor; $n=20$ ), red-necked wallaby (Notamacropus rufogriseus; $n=20$ ) and eastern grey kangaroo (Macropus giganteus; $n=20$ ) stomach samples collected between 2008-13 from Portland Aluminium Smelter, south-west Victoria 


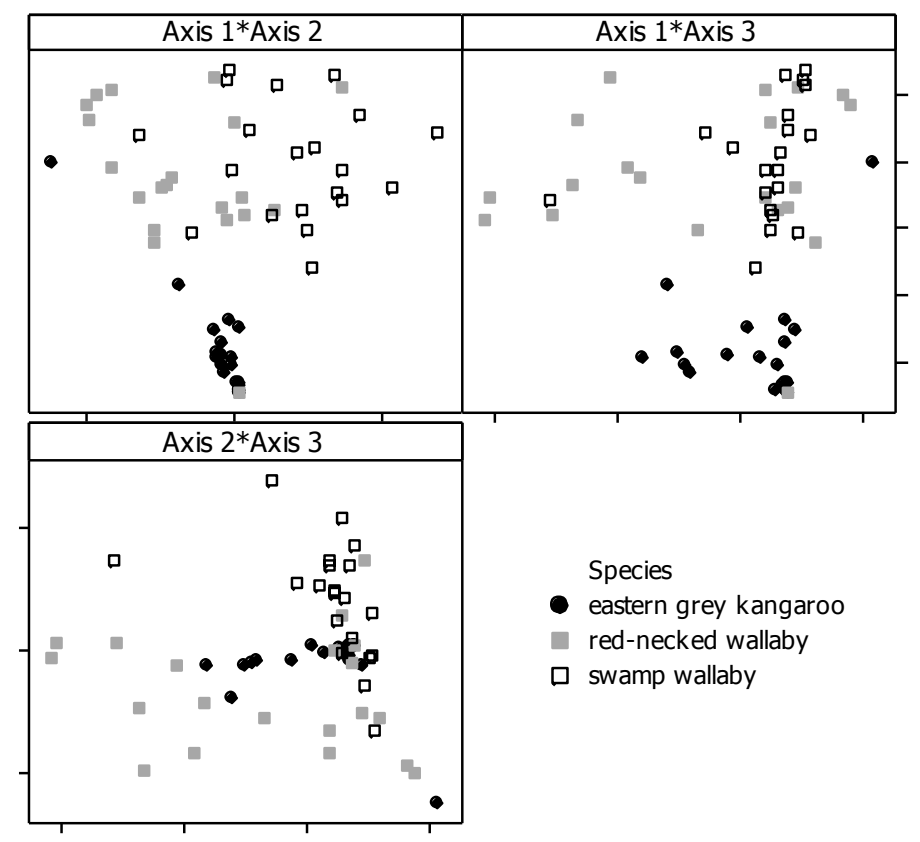

Fig. 5 Non-metric multi-dimensional scaling three-dimensional configuration (each axis displayed in two dimensions) of the diets of swamp wallaby (Wallabia bicolor; $n=20$ ), red-necked wallaby (Notamacropus rufogriseus; $n=20$ ) and eastern grey kangaroo (Macropus giganteus; $n=20$ ) based on a Bray-Curtis matrix of dissimilarities between the percentage of each plant functional group identified using microhistological techniques in stomach samples collected from Portland Aluminium Smelter, south-west Victoria between 2008-13 (stress $=0.05$ ). Standardisation (1) was applied within functional groups 


\section{University Library}

\section{- M M N E R VA A gateway to Melbourne's research publications}

Minerva Access is the Institutional Repository of The University of Melbourne

Author/s:

Davis, NE;Death, CE;Coulson, G;Newby, L;Hufschmid, J

Title:

Interspecific variation in the diets of herbivores in an industrial environment: implications for exposure to fluoride emissions

Date:

2016-05-01

Citation:

Davis, N. E., Death, C. E., Coulson, G., Newby, L. \& Hufschmid, J. (2016). Interspecific variation in the diets of herbivores in an industrial environment: implications for exposure to fluoride emissions. ENVIRONMENTAL SCIENCE AND POLLUTION RESEARCH, 23 (10), pp.10165-10176. https://doi.org/10.1007/s11356-016-6234-z.

Persistent Link:

http://hdl.handle.net/11343/282957 